\title{
Particle removal efficiency of a household portable air cleaner in real-world residences: A single-blind cross-over field study
}

Article

Accepted Version

Creative Commons: Attribution-Noncommercial-No Derivative Works 4.0

Cai, J., Yu, W., Li, B., Yao, R., Zhang, T., Guo, M., Wang, H., Zheng, Z., Xiong, J., Meng, Q. and Kipen, H. (2019) Particle removal efficiency of a household portable air cleaner in realworld residences: A single-blind cross-over field study. Energy and Buildings, 203. 109464. ISSN 0378-7788 doi:

https://doi.org/10.1016/j.enbuild.2019.109464 Available at https://centaur.reading.ac.uk/86707/

It is advisable to refer to the publisher's version if you intend to cite from the work. See Guidance on citing.

To link to this article DOI: http://dx.doi.org/10.1016/j.enbuild.2019.109464

Publisher: Elsevier

All outputs in CentAUR are protected by Intellectual Property Rights law, including copyright law. Copyright and IPR is retained by the creators or other copyright holders. Terms and conditions for use of this material are defined in the End User Agreement. 


\section{www.reading.ac.uk/centaur}

\section{CentAUR}

Central Archive at the University of Reading

Reading's research outputs online 
Particle removal efficiency of a household portable air cleaner in real-world residences: A single-blind cross-over field study

Jiao Cai ${ }^{\mathrm{a}, \mathrm{b}}$, Wei Yu${ }^{\mathrm{a}, \mathrm{b}, *}$, Baizhan Li ${ }^{\mathrm{a}, \mathrm{b}}$, Runming Yao ${ }^{\mathrm{a}, \mathrm{c}}$, Tujingwa Zhang ${ }^{\mathrm{a}, \mathrm{b}}$, Miao Guo ${ }^{\mathrm{a}, \mathrm{b}}$,

Han Wang ${ }^{a, b}$, Zhu Cheng ${ }^{a, b}$, Jie Xionga,b, Qingyu Meng ${ }^{\mathrm{d}, \mathrm{e}}$, Howard Kipen ${ }^{\mathrm{d}, \mathrm{e}}$

a Joint International Research Laboratory of Green Buildings and Built Environments (Ministry of Education), Chongqing University, Chongqing 400045, China

b National Centre for International Research of Low-carbon and Green Buildings (Ministry of Science and Technology), Chongqing University, Chongqing,

China

' School of the Built Environment, Whiteknights, University of Reading, UK

dSchool of Public Health, Rutgers University, USA

e Environmental and Occupational Health Sciences Institute, Rutgers University, USA

\section{Particle Removal Efficiency of a Household Portable Air Cleaner in Real-world Residences: A Single-blind Cross-over Field Study}

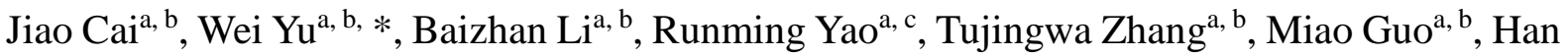

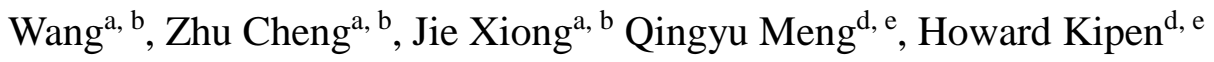

${ }^{\text {a }}$ Joint International Research Laboratory of Green Buildings and Built Environments (Ministry of Education), Chongqing University, Chongqing, China;

${ }^{\mathrm{b}}$ National Centre for International Research of Low-carbon and Green Buildings (Ministry of Science and Technology), Chongqing University, Chongqing, China;

${ }^{\mathrm{c}}$ School of the Built Environment, Whiteknights, University of Reading, UK

${ }^{\mathrm{d}}$ School of Public Health, Rutgers University, USA

${ }^{\mathrm{e}}$ Environmental and Occupational Health Sciences Institute, Rutgers University, USA

\section{*Corresponding Author:}

Prof. Wei Yu (Email address: yuweixscq@126.com) 
Joint International Research Laboratory of Green Buildings and Built Environments (Ministry of Education), Chongqing University, Chongqing, 400045, China.

Short Title: Household Air Cleaner for Indoor Air Particles 


\section{Abstract}

2 Portable air cleaners are commonly used to reduce indoor air particles in China, but few studies

3 have evaluated the treatment efficiency under real living conditions. We aimed to evaluate the

4 efficiency of a portable air cleaner in common residences under normal living conditions. A

5 single-blind cross-over field study was conducted in 20 urban residences in Chongqing, China.

6 In each residence, one portable air cleaner was operated without a high-efficiency particulate

7 air (HEPA) filter (sham filtration) for the first $48 \mathrm{~h}$ and with a HEPA filter (true filtration) for

8 the next $48 \mathrm{~h}$ in the living room. Concentrations of $\mathrm{PM}_{1.0}, \mathrm{PM}_{2.5}$, respirable suspended

9 particulate matter (RESP), $\mathrm{PM}_{10}$, and total suspended particulate matter (TSP) were measured

10 simultaneously in indoor and ambient outdoor air. Compared to sham filtration, the average

11 concentrations of indoor air particles were significantly lower when true filtration was used

12 according to paired-sample $t$-tests (all $p$-values $<0.05$ ). However, indoor concentrations of

$13 \quad \mathrm{PM}_{2.5}$ in $16(80 \%)$ residences were still higher than the World Health Organization's (WHO)

14 air quality guideline during true filtration. The removal efficiencies of the portable air cleaners with HEPA filters for these particles were about $40 \%$. The removal efficiencies for $\mathrm{PM}_{1.0}, \mathrm{PM}_{2.5}$, and RESP had significant associations with the room volume, but not with the residence district,

17 season, age of the building, floor level of the apartment, or ambient weather. Our results indicate that a portable air cleaner is effective in improving household air quality, but is not enough to ensure the air quality meeting WHO guideline in all real-world residences in polluted areas.

21 Keywords: Indoor air quality; Air cleaner; Infiltration factor; Residences 


\section{Introduction}

Indoor environmental pollution can have a great impact on human health because many people spend approximately $90 \%$ of their time in indoors [1, 2]. Natural ventilation is a common approach to dilute indoor pollutants emitted by indoor sources in residences. Epidemiological studies have shown that an increase in the air exchange rate can significantly improve indoor air quality and reduce the risks of allergic diseases in children [3-7]. However, ventilation also allows outdoor air pollutants to enter into the indoor environment when outdoor air quality is poor. In urban China, ambient air pollution is often serious and can lead to bad air indoor $\mathrm{PM}_{2.5}$ (particulate matter (PM) with aerodynamic diameters smaller than $2.5 \mu \mathrm{m}$ ) and outdoor $\mathrm{PM}_{2.5}$ had good correlations when there were no obvious $\mathrm{PM}_{2.5}$ sources in the indoor environment, and about $78 \%$ of the indoor $\mathrm{PM}_{2.5}$ came from outdoors $[8,9]$.

Additionally, many studies have reported that ambient pollution has significant adverse effects on human health [10-14]. A recent study found that external sources, rather than internal ones, were responsible for the presence of magnetite nanoparticles in the human brain, and these nanoparticles were probably present in the airborne particulate matter [10]. Another longitudinal cohort study analyzed the national and global burdens of diabetes attributable to ambient $\mathrm{PM}_{2.5}$ and found that a $10 \mu \mathrm{g} / \mathrm{m}^{3}$ increase of $\mathrm{PM}_{2.5}$ increased the risk of developing diabetes mellitus by $15 \%$ [11]. A nationwide study in China also indicated that a $10 \mu \mathrm{g} / \mathrm{m}^{3}$ increase of annual $\mathrm{PM}_{2.5}$ in outdoor environments had significant associations with pediatric allergic rhinitis and asthma and could increase the risk by $20 \%$ [13].

Therefore, it is important to find an effective and acceptable way to reduce indoor air 
particles that have infiltrated from outdoors via ventilation and those generated indoors from smoking, cooking, and other sources. In normal residential buildings, use of a portable air cleaner is a common method for reducing these particles. Current assessments of the removal efficiency of air cleaners for particulate matter conducted in environmental chambers are insufficient for reflecting the actual efficiency under real living and use conditions. Thus, field assessments are required to evaluate the actual efficiency of portable air cleaners. Such information would be valuable for developing guidelines for the use of these cleaners in residences. Several related studies have been conducted in residential buildings [15-20]. These studies found that portable air cleaners used in residences could reduce concentrations of 

knowledge, no study has evaluated the efficiency of a portable air cleaner in real-world residences in urban cities of south China, where household natural ventilation rates are often large and outdoor air quality is often bad. To fill this knowledge gap, in this study, we conducted a randomized single-blinded cross-over trial in Chongqing, China. We aimed to evaluate the distributions and characteristics of indoor and outdoor particle concentrations for residential buildings; to determine the correlation coefficients $(r)$ between indoor and outdoor particulate matter, and subsequently, compute the ambient contribution to indoor air particles when air cleaners were operated daily; and to evaluate the particle-removal efficiency of air cleaners under real world living conditions.

\section{Methods}

\subsection{Study subjects and intervention process}

During the period of July 2015 to January 2016, we conducted a 4-d intervention study on the indoor air particle-removal efficiency of household portable air cleaners in residences of the urban area of Chongqing city. These residences were selected according to the following principles: 1) no one smoked in the residence; 2) no central air purifier system was installed in the residence; 3 ) the residence was a multi-room apartment located in a multi-story building and was most commonly located in the urban area of Chongqing city. We recruited volunteers through notices in our laboratory and on the university website. A total of 20 residences were inspected [22]. Figure 1 shows the locations of the inspected residences. Participants were aged 25-40 years-old, and they generally left the residence during 9:00 am to 5:00 pm for work. 
87 Since these residences were real dwellings and were not experimental buildings, we defined that the studied particle-removal efficiency of household portable air cleaners was in "realworld" residences.

These residences were randomized into two groups during the intervention. To ensure that the inspected residents have little influence on the operating behavior of air cleaners, we used a single-blind cross-over design and the inspected residents did not know the intervention status (true or sham). During the intervention, the air cleaner was operated with sham filtration during the first $48 \mathrm{~h}$ and subsequently operated with true filtration during the next $48 \mathrm{~h}$. The air cleaner used in this study was a common portable air cleaner (Philips AC4374). The air cleaner for true filtration was equipped with a HEPA filter (Philips AC4138), while the air cleaner for sham of the inspected residences are given in Table 1.

\subsection{Data collection}

filtration was not equipped with any filter. Except for difference in filter, the air cleaner was operated completely in the same state in true and sham intervention. Building characteristics

In living rooms that are less than $50 \mathrm{~m}^{2}$, one to three sampling points are recommended according to the "Indoor Environment Air Quality Monitoring Technical Specifications" (HJ/T167-2004) [23]. Herein, we set up one sampling point approximately in the middle of the living room, and we avoided as much as possible the areas where inhabitants were active. The sampling point was set $1.3-1.5 \mathrm{~m}$ above the ground to reflect the height range of an adult's respiratory area. The outdoor sampling point was located 1.0-1.5 $\mathrm{m}$ away from an external wall. A simple bracket was used to connect the sampling instrument to a sampling tube, and 
the sampling tubes spanned from indoors to outdoors where the sampling device was placed on the balcony. The air cleaner was placed away from the indoor sampling points, windows, and doors, as well as from the wall more than $0.5 \mathrm{~m}$ and from areas of poor ventilation (such as corners) as much as possible. In order to obtain the household particle-removal efficiency of the air cleaners under real world conditions, subjects were allowed to use windows (either open or closed) as they preferred. During the sampling period, we allowed the occupants to maintain their lifestyle habits as was normal for them. The setup for monitoring the concentrations of indoor and outdoor pollutants in each dwelling is shown in Figure 2.

The target contaminant in this study was PM. Testing was conducted in two phases, namely, sham filtration (in the first $48 \mathrm{~h}$ ) and true filtration (in the next $48 \mathrm{~h}$ ). In both phases, the field sampling was conducted in the living room. In each residence, indoor and outdoor real-time air concentrations of $\mathrm{PM}_{1.0}, \mathrm{PM}_{2.5}$, RESP (respirable suspended particulate matter with aerodynamic diameters between 2.5 to $10 \mu \mathrm{m}$ ), $\mathrm{PM}_{10}$, and TSP (total suspended particulate matter with aerodynamic diameters of up to $100 \mu \mathrm{m}$ ) were measured simultaneously for $4 \mathrm{~d}$ (96 h). Two PM monitors (Dust Track 8534, TSI Inc, USA; detection range: 0.001 to 150 $\mathrm{mg} / \mathrm{m}^{3}$, accuracy: $\pm 0.1 \%$, resolution: $0.001 \mathrm{mg} / \mathrm{m}^{3}$ ) and temperature and humidity recorders (HOBO/UX100-011, USA; temperature: $-20-70{ }^{\circ} \mathrm{C}, \pm 0.21{ }^{\circ} \mathrm{C}, 0.024{ }^{\circ} \mathrm{C}$; relative humidity: $1 \% \sim 95 \%, \pm 2.5 \%, 0.05 \%)$ were used for indoor and outdoor measurements, and the sampling interval was set at $1 \mathrm{~min}$. The data display screens of these devices were masked to ensure that the inspected residents cannot see the measured data.

The same type of monitoring device was used in indoor and outdoor environments. During true filtration, purification involved a combination of adsorption and filtration. According to 
the product description of the HEPA filter, the clean air delivery rates (CADRs) of particulate matter and formaldehyde were $340 \mathrm{~m}^{3} / \mathrm{h}$ and $185 \mathrm{~m}^{3} / \mathrm{h}$, respectively. According to the method for calculating the applicable area of this air cleaner described in "Air Cleaner" (GB/T 188012015) [24], the calculated values were $23.8-40.8 \mathrm{~m}^{2}$. The largest area of the inspected living rooms was about $35 \mathrm{~m}^{2}$, which was within the scope of the purifier's capabilities.

\subsection{Formulas and models}

An alternative to the commonly used CADR approach, the particle-removal efficiency (PRE) takes into account the effect of an air cleaner on particles of different sizes. The particleremoval efficiency of the air cleaner in real-world residence can be calculated by the following formula:

$$
\mathrm{PRE}=\left(\left(C_{a c}-C_{i c}\right) / C_{a c}\right) \times 100 \%
$$

where $C_{a c}$ is the measured outdoor air particle concentration $\left(\mathrm{PM}_{1.0}, \mathrm{PM}_{2.5}, \mathrm{RESP}, \mathrm{PM}_{10}\right.$, and TSP), and $C_{i c}$ is the corresponding indoor air particle concentration.

For evaluating the ambient contribution to indoor air particles, the Random Component Superposition (RCS) model was applied [25]. This model is based on the statistical interrelationships among variables obtained in field study measurements. This model assumes that indoor and outdoor PM concentrations are at steady state, and that ambient sources and non-ambient sources are independent. The model allows for sample-to-sample variation (across homes and days) in air exchange rates, particle penetration, and particle loss rates that can occur due to variations in parameters such as the house structure, air conditioner use, ventilation practice, particle size distribution, particle composition, and thermodynamic 
stability of particle species. In this model, indoor air PM concentrations were separated into the following two parts: ambient contribution $\left(C_{a}\right)$ and non-ambient contribution $\left(C_{n a}\right)$. The ambient contribution $\left(C_{a}\right)$ is computed from the product of the measured outdoor air PM concentration $\left(C_{a c}\right)$ and infiltration factor $\left(F_{I N F}\right)$, and it is a combined factor reflecting the penetration coefficient, air exchange rate, and indoor particle loss rate. In each residence, the infiltration factor $\left(F_{I N F}\right)$ was estimated by the least-trimmed squared method with a linear regression model and can be calculated by the following equation [26]:

$$
F_{I N F}=\frac{\mathrm{a} P}{\mathrm{a}+K}
$$

where $a$ is the air exchange rate due to infiltration; $P$ is the particle penetration factor; and $K$ is the particle deposition rate.

The ambient contribution $\left(C_{a}\right)$ was calculated with the estimated $F_{I N F}$ and with the measured outdoor PM concentration $\left(C_{a c}\right)$. The proportion of the ambient contribution to indoor air PM concentrations was also calculated. During both of the periods of sham filtration and true filtration, the $F_{I N F}$ and ambient contribution were compared by the $t$-test and $F$-test, respectively. The RCS model is as follows:

$$
C_{i c}=C_{a}+C_{n a}=F_{I N F} C_{a c}+C_{n a}
$$

\subsection{Statistical analyses}

All statistical analyses were performed with SPSS 22.0 for Windows (IBM Inc., USA). We converted the sampling data from minutes to hourly data and calculated the hourly and total mean value as well as the corresponding standard deviation of indoor and outdoor pollutants both during true filtration and sham filtration through pivot tables. The indoor and outdoor 
particle concentrations were normally distributed in each residence according to KolmogorovSmirnov testing.

The data analysis consisted of the following three steps: 1) evaluating the influence of true filtration and sham filtration on particle concentrations in dwellings; 2) evaluating the ambient contributions to indoor air particles during the use of an air cleaner; 3) evaluating the removal efficiency of an air cleaner. In the first step, the data analysis was performed based on the 48$\mathrm{h}$ averaged value of measured indoor and outdoor air particle concentrations when the air cleaner was operated with sham filtration $v s$. true filtration in each residence. The differences between indoor and outdoor air particle concentrations during the periods with sham filtration and true filtration were estimated by comparing the mean values in independent-sample $t$-tests. The differences in indoor and outdoor air particle concentrations between sham filtration and true filtration were estimated by comparing the mean values in paired-sample $t$-tests. In the second step, we calculated the Spearman's correlation coefficient $(r)$ between indoor and outdoor particulate matter in each residence and in all residences. The contributions of ambient particles to indoor air particles were estimated by using general linear model regression analyses. In the third step, we calculated the removal efficiency for particles in each residence. By using a one-way analysis of variance (ANOVA) test, we also compared the reduction efficiency for particles in the residences under different conditions. Significance was set at a $p$ value smaller than 0.05 , and $95 \%$ confidence intervals $(95 \% \mathrm{CI})$ were also calculated.

\section{Results}

The hourly changes in concentrations of $\mathrm{PM}_{2.5}$ and $\mathrm{PM}_{10}$ in indoor and outdoor air during 
the experiments in each residence are shown in Figure 3 and Figure 4, respectively. The $\mathrm{PM}_{2.5}$ and $\mathrm{PM}_{10}$ concentrations varied notably in these residences. The outdoor concentrations of $\mathrm{PM}_{2.5}$ and $\mathrm{PM}_{10}$ were generally higher than the indoor concentrations during all inspected durations. During the true filtration (from $48 \mathrm{~h}$ to $96 \mathrm{~h}$ ), indoor concentrations of $\mathrm{PM}_{2.5}$ and $\mathrm{PM}_{10}$ were substantially lower than outdoor concentrations in most inspected residences. The correlation coefficient $(r)$ between indoor and outdoor $\mathrm{PM}_{2.5}$ and $\mathrm{PM}_{10}$ concentrations ranged from 0.142 to 0.962 and from 0.114 to 0.958 , respectively. Except for four residences (coded 03, 05, 07, and 15), the indoor $\mathrm{PM}_{2.5}$ concentrations were still generally higher than the World Health Organization (WHO) air quality guidelines [27] under the true filtration. However, only four residences (coded 10,11, 14, and 17) had indoor $\mathrm{PM}_{10}$ concentrations that were still generally higher than the WHO air quality guidelines under the true filtration. Similar trends were found for indoor and outdoor concentrations of $\mathrm{PM}_{1.0}$, RESP, and TSP (data not presented). Table 2 shows the mean values and standard deviations of indoor and outdoor concentrations for $\mathrm{PM}_{1.0}, \mathrm{PM}_{2.5}, \mathrm{RESP}, \mathrm{PM}_{10}$, and TSP with sham filtration and true filtration. During sham filtration, the mean values of outdoor and indoor PM concentrations in different fractions ranged from $59.0 \mu \mathrm{g} / \mathrm{m}^{3}$ to $71.5 \mu \mathrm{g} / \mathrm{m}^{3}$ and from $48.2 \mu \mathrm{g} / \mathrm{m}^{3}$ to $57.1 \mu \mathrm{g} / \mathrm{m}^{3}$, respectively. During true filtration, the mean values of outdoor and indoor PM concentrations in different fractions ranged from $52.9 \mu \mathrm{g} / \mathrm{m}^{3}$ to $63.9 \mu \mathrm{g} / \mathrm{m}^{3}$ and from $31.2 \mu \mathrm{g} / \mathrm{m}^{3}$ to $37.3 \mu \mathrm{g} / \mathrm{m}^{3}$, respectively. The paired-sample $t$-tests indicated that outdoor air PM concentrations were not significantly different between the sham filtration and true filtration experiments, whereas indoor air PM concentrations during the true filtration were significantly lower than those during sham filtration ( $p$-values are shown in Table S1). According to the independent-sample 
$t$-tests (Table 2), indoor air PM concentrations showed no significant differences from outdoor air PM concentrations during the sham filtration, whereas all PM concentrations indoors had significant differences with outdoor air PM concentrations during the true filtration. We also observed that indoor air PM concentrations had strong correlations with outdoor air PM concentrations both during sham filtration and true filtration. All correlation coefficients between indoor PM concentrations and outdoor PM concentrations for the sham filtration were larger than those for the true filtration.

Table 3 shows the infiltration factor in the RCS model obtained by linear regression.

During sham filtration, the $F_{I N F}$ for $\mathrm{PM}_{1.0}, \mathrm{PM}_{2.5}, \mathrm{RESP}, \mathrm{PM}_{10}$, and TSP was 0.933, 0.921, 0.910,

0.931 , and 0.939 , respectively, and all of the $p$-values were smaller than 0.001 . During true filtration, the $F_{I N F}$ for $\mathrm{PM}_{1.0}, \mathrm{PM}_{2.5}, \mathrm{RESP}, \mathrm{PM}_{10}$, and TSP was $0.530,0.535,0.539,0.558$, and 0.568 , respectively, and all of the $p$-values were smaller than 0.001 . The decrease in the infiltration factor amounted to $0.403,0.386,0.371,0.373$, and 0.371 , respectively. Figure 5 shows the linear fitting models for indoor and outdoor $\mathrm{PM}_{1.0}, \mathrm{PM}_{2.5}, \mathrm{RESP}, \mathrm{PM}_{10}$, and TSP. These results show that there were linear relationships for both durations, and stronger linear relationships were found during sham filtration than during true filtration. The $\mathrm{R}^{2}$ values (sham filtration vs. true filtration) were $0.89 v s .0 .76,0.88 v s .0 .59,0.89 v s .0 .74,0.85 v s .0 .74$, and 0.88 vs. 0.74 for $\mathrm{PM}_{1.0}, \mathrm{PM}_{2.5}, \mathrm{RESP}, \mathrm{PM}_{10}$, and TSP, respectively.

Figure 6 and Table S2 show the reduction efficiencies for $\mathrm{PM}_{1.0}, \mathrm{PM}_{2.5}, \mathrm{RESP}, \mathrm{PM}_{10}$, and TSP in each inspected residence, and these efficiencies ranged from 0.02 to $0.76,0.05$ to 0.77 , 0.09 to $0.77,0.11$ to 0.78 , and 0.12 to 0.78 , respectively. The particle-removal efficiencies and their distributions were similar for all PM types in each residence. Except for residences coded 
23708 and 14 , the particle-removal efficiencies were greater than $20 \%$. The particle-removal 238 efficiencies in about half of the inspected residences were $>40 \%$. Two residences (coded 03 239 and 15) had particle-removal efficiencies of approximately 75\%. The mean values of reduction 240 efficiencies of the 20 residences for $\mathrm{PM}_{1.0}, \mathrm{PM}_{2.5}, \mathrm{RESP}, \mathrm{PM}_{10}$, and TSP were $39 \%, 40 \%, 40 \%$, $24141 \%$, and $41 \%$, respectively (Table 4).

Table 4 shows the particle-removal efficiencies in the residences under different conditions. Compared to residences that had opened windows during the inspection, residences that kept the windows closed had significantly higher particle-removal efficiencies for TSP. The reduction efficiencies for $\mathrm{PM}_{1.0}, \mathrm{PM}_{2.5}$, and RESP had significant associations with the room volume, with larger room volumes showing lower reduction efficiencies. However, although values of the reduction efficiencies were different, the reduction efficiencies were not ambient weather.

\section{Discussion}

In this randomized cross-over field study, we found that $\mathrm{PM}_{2.5}$ and $\mathrm{PM}_{10}$ concentrations both indoors and outdoors were generally higher than the WHO air quality guidelines (25 $\mu \mathrm{g} / \mathrm{m}^{3}$ for $\mathrm{PM}_{2.5}$ and $50 \mu \mathrm{g} / \mathrm{m}^{3}$ for $\mathrm{PM}_{10}$ ) in Chongqing residences, although indoor concentrations of $\mathrm{PM}_{1.0}, \mathrm{PM}_{2.5}, \mathrm{RESP}, \mathrm{PM}_{10}$, and TSP were significantly decreased by using a portable air cleaner with a HEPA filter. Indoor and outdoor PM concentrations showed high correlations (correlation efficient (r): 0.859-0.941) and strong linear relationships. Outdoor 
respectively. The particle-removal efficiencies of portable air cleaners for all studied PM types varied in different residences with an average of $40 \%$. Indoor concentrations of $\mathrm{PM}_{2.5}$ in $80 \%$ of the residences were still generally higher than the $\mathrm{WHO}$ air quality guideline under the true filtration. Room volume had a great effect on the particle-removal efficiencies for $\mathrm{PM}_{1.0}, \mathrm{PM}_{2.5}$, and RESP, and the efficiencies increased as the room volume decreased.

The ambient concentrations of $\mathrm{PM}_{2.5}$ and $\mathrm{PM}_{10}$ in this study were similar to many previous studies in Chongqing and in other cities. A review for ambient $\mathrm{PM}_{2.5}$ in 45 global megacities found that Delhi, Cairo, Xi'an, Tianjin, and Chengdu were the five most polluted megacities with an annual average concentrations $>89 \mu \mathrm{g} / \mathrm{m}^{3}$ in 2013 [28]. In 2005, the annual average $\mathrm{PM}_{2.5}$ concentration in Shanghai was $56 \mu \mathrm{g} / \mathrm{m}^{3}$ [29]. From March 2013 to April 2014, the satellite derived population-weighted average $\mathrm{PM}_{2.5}$ concentration in Beijing was $51.2 \mu \mathrm{g} / \mathrm{m}^{3}$ [30]. In 2009, the annual average concentration of $\mathrm{PM}_{10}$ in 113 major Chinese cities was 87 $\mu \mathrm{g} / \mathrm{m}^{3}$ [31]. In this study, the average concentrations of ambient $\mathrm{PM}_{2.5}$ and $\mathrm{PM}_{10}$ (from July 2015 to January 2016) were 62.1 and $70.0 \mu \mathrm{g} / \mathrm{m}^{3}$, respectively, which were levels notably higher than the WHO global air quality guidelines $\left(25 \mu \mathrm{g} / \mathrm{m}^{3}\right.$ for $\mathrm{PM}_{2.5}$ and $50 \mu \mathrm{g} / \mathrm{m}^{3}$ for $\mathrm{PM}_{10}$ ) [27]. These findings suggest that ambient air pollution of $\mathrm{PM}_{2.5}$ and $\mathrm{PM}_{10}$ is still a serious problem in Chongqing and other cities of China. More efforts are warranted to control these pollutants.

Our findings that indoor PM concentrations had strong linear correlations $\left(\mathrm{R}^{2}=73 \%-\right.$ 89\%) with outdoor PM concentrations are consistent with other similar studies [32-35]. In a study conducted in Brisbane, Australia, researchers measured indoor and outdoor airborne particles in 16 residential houses and found that the indoor/outdoor (I/O) ratio for the $\mathrm{PM}_{2.5}$ 
fraction ranged from 1.01 to 1.08 [32]. This study also found that instantaneous indoor particle concentrations could be predicted by outdoor particle concentrations under normal ventilation conditions (air exchange rate $\geq 2 \mathrm{~h}^{-1}$ ), since a clear positive relationship existed between indoor and outdoor particle concentrations [32]. Dai et al. [33] monitored indoor air quality in 117 Chinese homes and found that the naturally ventilated homes had a median I/O ratio of around 0.88-0.97 when the outdoor $\mathrm{PM}_{2.5}$ concentration was lower than $75 \mu \mathrm{g} / \mathrm{m}^{3}$. Huang et al. [34] inspected about 450 Shanghai residences in different seasons and reported that indoor and outdoor concentrations of particulate matter $\left(\mathrm{PM}_{2.5}\right.$ and $\left.\mathrm{PM}_{10}\right)$ had strong linear correlations $(r$ $=0.891-0.922 ; p$-value $<0.001)$. A study from the USA measured 48-h concentrations of indoor and outdoor $\mathrm{PM}_{2.5}$ in 374 non-smoking homes and also found that $20 \%-90 \%$ of indoor exposures to $\mathrm{PM}_{2.5}$ could be attributed to ambient outdoor $\mathrm{PM}_{2.5}$, which was the dominant predictor of indoor $\mathrm{PM}_{2.5}$ concentrations $\left(\mathrm{R}^{2}=30 \%-70 \%\right)$ [35]. These findings indicate that decreasing the infiltration of ambient airborne particles into indoor environments is a useful approach for reducing indoor particle exposures in residences without major indoor sources of airborne particles.

The particle-removal efficiencies (about 40\%) of portable air cleaners for different PM types in this study were lower than those in many previous studies [20, 36-40]. In a study from Seoul, Korea, researchers evaluated the removal efficiencies of an air purifier (LA-R119SWF, Korea) for $\mathrm{PM}_{2.5}$ and $\mathrm{PM}_{10}$ in 10 childcare centers during summer, autumn, and winter and found that the removal efficiencies ranged from $75 \%-78 \%$ for $\mathrm{PM}_{2.5}$ and $72 \%-84 \%$ for $\mathrm{PM}_{10}$ [36]. A randomized cross-over study from Denmark found that the removal efficiency of particle filtration units (PFUs) for $\mathrm{PM}_{2.5}$ was $54.5 \%$ (median-averaged) over a 2-week 
intervention in 27 residences [37]. Another placebo-controlled cross-over study used a HEPA cleaner and a placebo "dummy" in homes for 4 weeks each and found that the measured $\mathrm{PM}_{2.5}$ concentration was significantly reduced following HEPA filtration, and thus, it was concluded that HEPA air purification could result in a significant reduction of $\mathrm{PM}_{2.5}$ in indoor air in diverse residential settings [20]. In China, the operating behaviors and performances of portable air cleaners were evaluated in 43 residential buildings during June 2017 to December 2017, and results showed that the removal efficiency for $\mathrm{PM}_{2.5}$ ranged from $42 \%$ to $88 \%$ [38]. A randomized cross-over study in Beijing residences, which was conducted by using a prefilter+HEPA+carbon-filter air cleaner, found that the average indoor $\mathrm{PM}_{2.5}$ concentration during true filtration was $8.47 \mu \mathrm{g} / \mathrm{m}^{3}$ (49.0 $\mu \mathrm{g} / \mathrm{m}^{3}$ during sham filtration), which is lower than the WHO guideline level [40]. These differences in the removal efficiency for indoor airborne particles in different studies could have several explanations. First, different types of filters used in the air purifier could lead to different results. Second, the operating behavior of the air purifier could have been different in the different studies. Third, the numbers and ages of the occupants, as well as times that the occupants presented in the residences would cause disturbance in the air flow and thus might affect the efficiency. The occupants also likely contributed to particles becoming airborne (resuspension) or causing emission that contribute to indoor air concentrations of PM (e.g. cooking). In this study, the graphic concentration-time pattern in Figure 3 (e.g. 3, 6, 12, 17, 18, 19, and 20) and Figure 4 (e.g. 3, 4, 6, 12, 15, 17, 19, and 20) suggests that there may be an impact (where the indoor concentration deviates from the outdoor pattern and range). Fourthly, building characteristics (volume and ventilation condition) of the studied rooms and ambient air pollution also varied in the different studies. 
324 Nevertheless, the removal efficiencies for indoor $\mathrm{PM}_{2.5}$ in the above studies were not smaller than $40 \%$. Findings in these studies suggest that portable air cleaners can be an effective device for reducing exposures to indoor airborne particles, but more than one portable air cleaner should be operated in urban residences with large room volumes or during poor ambient air quality to meet the WHO guidelines for $\mathrm{PM}_{2.5}$ and $\mathrm{PM}_{10}$ in China.

In this study, we found that only volume of the studied room had significant associations with the particle-removal efficiencies for $\mathrm{PM}_{1.0}, \mathrm{PM}_{2.5}$, and RESP, and that whether windows of the inspected rooms were closed had significant associations with the particle-removal efficiencies for TSP. This finding was inconsistent with the randomized cross-over study from Denmark [37]. In the Danish study, the floor level of the inspected room also had no significant association with the reduction efficiency of the air cleaners for indoor $\mathrm{PM}_{2.5}$ concentrations [37]. This finding is consistent with our findings in the present study (Table 4). These findings seemingly suggest that floor level is not an important factor for the particle-removal efficiency of an air cleaner.

This study had some limitations. We did not consider the indoor ventilation rate and ambient traffic close to the residences, which could have significant associations with the levels of indoor airborne particles and the particle-removal efficiencies of indoor air cleaners for particles as shown in the previous studies [36-38]. The inspected residences also were restricted as non-smoking multi-room apartments that located in a multi-story building and was most commonly located in the urban area of Chongqing city, as well as were without central air purifier system. The studied particle-removal efficiency of household air cleaner might cannot generalize to other types of residences. Nevertheless, to our best knowledge, this study 
is the first field study on the particle-removal efficiency of portable air cleaners conducted under actual conditions with a randomized single-blinded cross-over design in China. The primary strength of the cross-over design is that the on-site measured PM concentrations can be compared both within each residence under two different conditions and among different residences. The single-blind design also ensures that the inspected residents have little influence on the operating behavior of air cleaners (within comparisons), and thus, this increases the likelihood that the same interventions were conducted in different residences.

\section{Conclusions}

Ambient pollution of $\mathrm{PM}_{2.5}$ and $\mathrm{PM}_{10}$ remain serious health threats in different seasons in Chongqing, China. Indoor and outdoor airborne particle concentrations were found to have strong linear correlations. Use of a portable air cleaner with a HEPA filter was found to be an effective intervention method to improve indoor air quality, and air cleaners decreased by an average of $40 \%$ the indoor concentrations of $\mathrm{PM}_{1.0}, \mathrm{PM}_{2.5}, \mathrm{RESP}, \mathrm{PM}_{10}$, and TSP in urban residences under normal conditions. The particle-removal efficiencies of portable air cleaners with the HEPA filter were primarily affected by the volume of the inspected room, but not other building characteristics. To meet the WHO guidelines for $\mathrm{PM}_{2.5}$ and $\mathrm{PM}_{10}$, more than one cleaner should be operated in urban residences with large room volumes or during poor ambient air quality in China.

\section{Acknowledgments}

We sincerely appreciate all of the support and help from volunteers, teachers, and inspectors who participated and contributed to this research. We thank Prof. Hazim Awbi from the 
367 University of Reading, UK for his careful and professional revision of language.

368 Funding: This work was supported by the China Fundamental Research Funds for the Central 369 Universities [Grant No. 2018CDJDCH0015, 2019CDYGYB023], the Graduate Scientific 370 Research and Innovation Foundation of Chongqing, China [Grant No. CYB19031], the 371 Institute of International Education funded Global Innovation Initiative (GII) Project "The impact of ambient air pollution on indoor environment in China: Evaluation of a practical 373 intervention" [Grant No. EGA/A.S/S-13-05], NIEHS P30 ES005022, Institute for International 374 Education (RQ1943), and U.S. EPA (RD-83575901).

\section{Declaration of interest}

376 The authors report no conflicts of interest.

\section{Supplemental materials}

378 Table S1. Comparison of PM concentrations under sham filtration and true filtration.

379 Table S2. Removal efficiency for PM in each inspected residence. 


\section{References}

[1] F. Wu, D. Jacobs, C. Mitchell, D. Miller, M.H. Karol, Improving indoor environmental quality for public health: impediments and policy recommendations, Environ. Health Perspect. 115 (2007) 953-957.

[2] N.E. Klepeis, W.C. Nelson, W.R. Ott, J.P. Robinson, A.M. Tsang, P. Switzer, J.V. Behar, S.C. Hern, W.H. Engelmann, The National Human Activity Pattern Survey (NHAPS): a resource for assessing exposure to environmental pollutants, J. Expo. Sci. Environ. Epid. $11(3)(2001) 231-252$.

[3] C.G. Bornehag, J. Sundell, L. Hägerhed-Engman, T. Sigsgaard, Association between ventilation rates in 390 Swedish homes and allergic symptoms in children, Indoor Air 15 (2005) 275-280.

[4] W. Liu, C. Huang, Y. Hu, Z.J. Zou, Z.H. Zhao, J. Sundell, Association of building characteristics, residential heating and ventilation with asthmatic symptoms of preschool children in Shanghai: a cross-sectional study, Indoor Built Environ. 23 (2014) 270-283.

[5] Y.H. Mi, D. Norbäck, J. Tao, Y.L. Mi, M. Ferm, Current asthma and respiratory symptoms among pupils in Shanghai, China: influence of building ventilation, nitrogen dioxide, ozone, and formaldehyde in classrooms, Indoor Air 16 (2006) 454-464.

[6] P. Wargocki, J. Sundell, W. Bischof, G. Brundrett, P.O. Fanger, F. Gyntelberg, S.O. Hanssen, P. Harrison, A. Pickering, O. Seppänen, P. Wouters, Ventilation and health in non-industrial indoor environments: report from a European multidisciplinary scientific consensus meeting (EUROVEN), Indoor Air 12 (2002) 113-128. 
[7] J. Sundell, Reflections on the history of indoor air science, focusing on the last 50 years, Indoor Air 27 (2017) 708-724.

[8] E. Abt, H.H. Suh, G. Allen, P. Koutrakis, Characterization of indoor particle sources: A study conducted in the metropolitan Boston area, Environ. Health Perspect. 108 (1) (2000) $35-44$.

[9] R. Allen, T. Larson, L. Sheppard, L. Wallace, L.J. Liu, Use of real-time light scattering data to estimate the contribution of infiltrated and indoor-generated particles to indoor air, Environ. Sci. Technol. 37 (2003) 3484-3492.

[10] B.A. Maher, I.A.M. Ahmed, V. Karloukovski, D.A. MacLaren, P.G. Foulds, D. Allsop, D.M.A. Mann, R. Torres-Jardón, L. Calderon-Garciduenas, Magnetite pollution nanoparticles in the human brain, Proc. Natl. Acad. Sci. USA 113 (39) (2016) $10797-$ 10801.

[11] B. Bowe, Y. Xie, T. Li, Y. Yan, H. Xian, Z. Al-Aly, The 2016 global and national burden of diabetes mellitus attributable to PM2.5 air pollution, Lancet Planet. Health 2 (2018) e301-e312.

[12] C.J. Sun, J.L. Zhang, Y.C. Guo, Q.Y. Fu, W. Liu, J. Pan, Y.M. Huang, Z.J. Zou, C. Huang, Outdoor air pollution in relation to sick building syndrome (SBS) symptoms among residents in Shanghai, China, Energ. Build. 174 (2018) 68-76.

[13] F. Chen, Z.J. Lin, R.J. Chen, D. Norbäck, C. Liu, H.D. Kan, Q.H. Deng, C. Huang, Y. Hu, Z.J. Zou, W. Liu, J. Wang, C. Lu, H. Qian, X. Yang, X. Zhang, F. Qu, J. Sundell, Y.P. Zhang, B.Z. Li, Y.X. Sun, Z.H. Zhao, The effects of $\mathrm{PM}_{2.5}$ on asthmatic and allergic diseases or symptoms in preschool children of six Chinese cities, based on China, 
Children, Homes and Health (CCHH) project, Environ. Pollut. 232 (2018) 329-337.

[14] C. Arnold, Disease burdens associated with PM2.5 exposure: how a new model provided global estimates, Environ. Health Perspect. 122 (4) (2014) A111.

[15] M. Kajbafzadeh, M. Brauer, B. Karlen, C. Carlsten, S. van Eeden, R.W. Allen, The impacts of traffic-related and woodsmoke particulate matter on measures of cardiovascular health: a HEPA filter intervention study, Occup. Environ. Med. 72(6) (2015) 394-400.

[16] S. Batterman, L. Du, G. Mentz, B. Mukherjee, E. Parker, C. Godwin, J.Y. Chin, A. O’Toole, T. Robins, Z. Rowe, T. Lewis, Particulate matter concentrations in residences: an intervention study evaluating stand-alone filters and air conditioners, Indoor Air 22 (3) (2012) 235-252.

[17] B.P. Lanphear, R.W. Hornung, J. Khoury, K. Yolton, M. Lierl, A. Kalkbrenner, Effects of HEPA air cleaners on unscheduled asthma visits and asthma symptoms for children exposed to secondhand tobacco smoke, Pediatrics 127 (1) (2011) 93-101.

[18] M.L. McNamara, J. Thornburg, E.O. Semmens, T.J. Ward, C.W. Noonan, Reducing indoor air pollutants with air filtration units in wood stove homes, Sci. Tot. Environ. 592 (2017) 488-494.

[19] C. Godwin, C. Jia, Long duration tests of room air filters in cigarette smokers' homes, Environ. Sci. Technol. 39 (18) (2005) 7260-7268.

[20] J. Cox, K. Isiugo, P. Ryan, S.A. Grinshpun, M. Yermakov, C. Desmond, R. Jandarov, S. Vesper, J. Ross, S. Chillrud, K. Dannemiller, T. Reponen, Effectiveness of a portable air cleaner in removing aerosol particles in homes close to highways, Indoor Air 28 (2018) 
818-827.

[21] K.T. Kanatani, M. Okumura, S. Tohno, Y. Adachi, K. Sato, T. Nakayama, Indoor particle counts during Asian dust events under everyday conditions at an apartment in Japan, Environ. Health Prevent. Med. 19 (1) (2014) 81-88.

[22] B.Z. Li, Z. Cheng, R.M. Yao, H. Wang, W. Yu, Z.M. Bu, J. Xiong, T. Zhang, E. Essah, Z. Luo, M. Shahrestani, H. Kipen, An investigation of formaldehyde concentration in residences and the development of a model for the prediction of its emission rates, Build. Environ. 147 (2019) 540-550.

[23] HJ/T 167-2004, 2004. Technical Specifications for Monitoring of Indoor Air Quality. China: State Environmental Protection Administration of China.

[24] GB/T 18801-2015, 2015. Air Cleaner. China Standards Press.

[25] W. Ott, L. Wallace, D. Mage, Predicting particulate (PM10) personal exposure distributions using a random component superposition statistical model, J. Air Waste Manag. Assoc. 50 (8) (2000) 1390-1406.

[26]C. Chen, B. Zhao. Review of relationship between indoor and outdoor particles: I/O ratio, infiltration factor and penetration factor, Atmos. Environ. 45 (2) (2011): 275-288.

[27] World Health Organization (WHO), Air Quality Guidelines-Global Update 2005. World Health Organization, 2005, ISBN 92890219.

[28] Z. Cheng, L. Luo, S. Wang, Y. Wang, S. Sharma, H. Shimadera, X. Wang, M. Bressi, R.M. de Miranda, J. Jiang, W. Zhou, O. Fajardo, N. Yan, J. Hao, Status and characteristics of ambient PM2.5 pollution in global megacities, Environ. Int. 89-90 (2016) 212-221.

[29] H. Kan, S.J. London, G. Chen, Y. Zhang, G. Song, N. Zhao, L. Jiang, B. Chen, 
Differentiating the effects of fine and coarse particles on daily mortality in Shanghai, China, Environ. Int. 33 (2007) 376-384.

[30] Y. Xie, Y. Wang, K. Zhang, W. Dong, B. Lv, Y. Bai, Daily estimation of ground-level PM2.5 concentrations over Beijing using 3 km resolution MODIS AOD, Environ. Sci. Technol. 49 (2015) 12280-12288.

[31] Chinese Ministry of Environmental Protection, 2010. China Environmental Yearbook. Beijing: China Environmental Yearbook.

[32] L. Morawska, C. He, J. Hitchins, D. Gilbert, S. Parappukkaran, The relationship between indoor and outdoor airborne particles in the residential environment, Atmos. Environ. 35 (2001) 3463-3473.

[33] X.L. Dai, J.J. Liu, X.D. Li, L. Zhao, Long-term monitoring of indoor $\mathrm{CO}_{2}$ and PM2.5 in Chinese homes: Concentrations and their relationships with outdoor environments, Build. Environ. 144 (2018) 238-247.

[34] C. Huang, X.Y. Wang, W. Liu, J. Cai, L. Shen, Z.J. Zou, R.C. Lu, J. Chang, X.Y. Wei, C.J. Sun, Z.H. Zhao, Y.X. Sun, J. Sundell, Household indoor air quality and its associations with childhood asthma in Shanghai, China: On-site inspected methods and preliminary results, Environ. Res. 151 (2016) 154-167.

[35] Q.Y. Meng, D. Spector, S. Colome, B. Turpin, Determinants of indoor and personal exposure to $\mathrm{PM}_{2.5}$ of indoor and outdoor origin during the RIOPA study, Atmos. Environ. 43 (2009) 5750-5758.

[36] H.J. Oh, I.S. Nam, H. Yun, J. Kim, J. Yang, J.R. Sohn, Characterization of indoor air quality and efficiency of air purifier in childcare centers, Korea, Build. Environ. 82 (2014) 
[37] M.P. Spilak, G.D. Karottki, B. Kolarik, M. Frederiksen, S. Loft, L. Gunnarsen, Evaluation of building characteristics in 27 dwellings in Denmark and the effect of using particle filtration units on PM2.5 concentrations, Build. Environ. 73 (2014) 55-63.

[38] J.J. Pei, C.B. Dong, J.J. Liu, Operating behavior and corresponding performance of portable air cleaners in residential buildings, China, Build. Environ. 147 (2019) 473-481.

[39] L. Wallace, 2018. Effectiveness of home air cleaners in reducing indoor levels of particles. Final Report, Health Canada Contract \# 4500172935.

[40] Y. Zhan, K. Johnson, C. Norris, M.M. Shafer, M.H. Bergin, Y.P. Zhang, J.F. Zhang, J.J. Schauer, The influence of air cleaners on indoor particulate matter components and oxidative potential in residential households in Beijing, Sci. Tot. Environ. 626 (2018), $507-518$. 


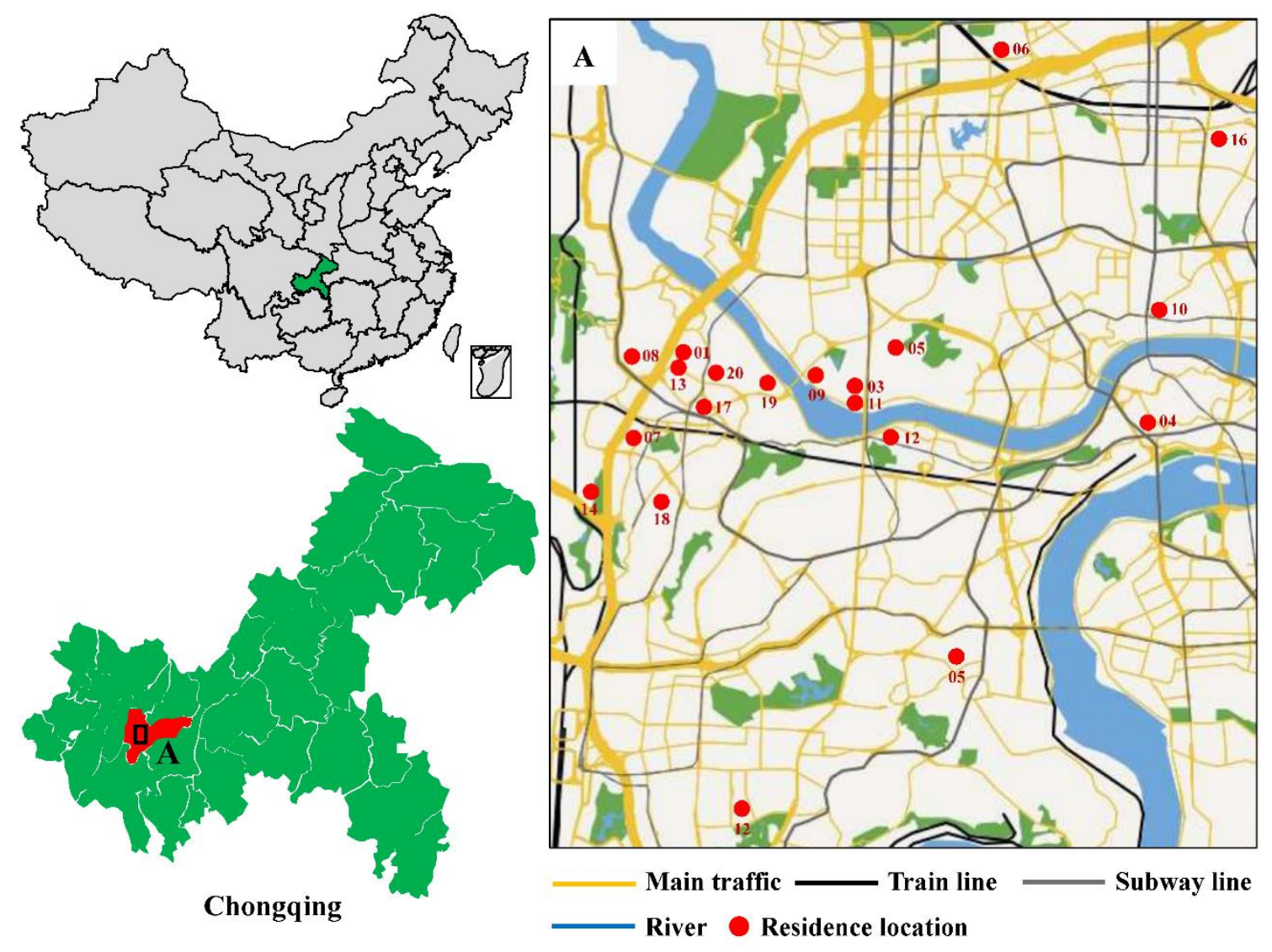

Figure 1. Location of the inspected residences. 


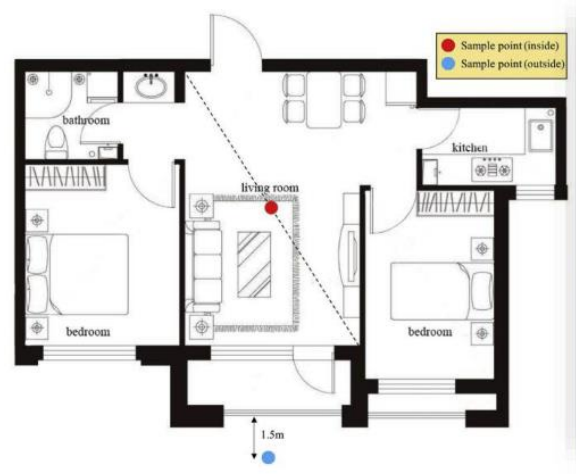

(a) Sample site

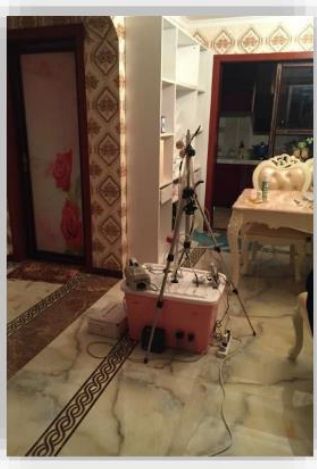

(b) Indoor sample point

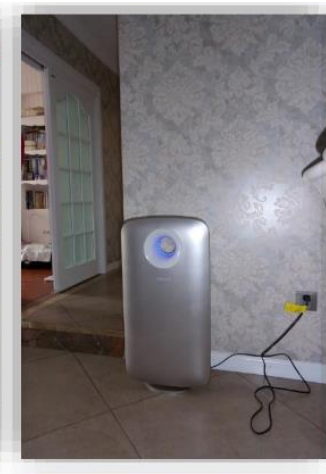

(c) Air cleaner

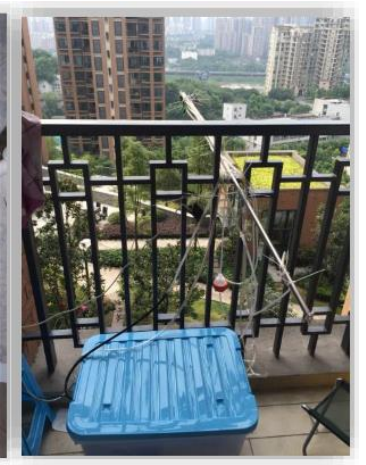

(d) Outdoor sample point

Figure 2. Sample site and equipment. 


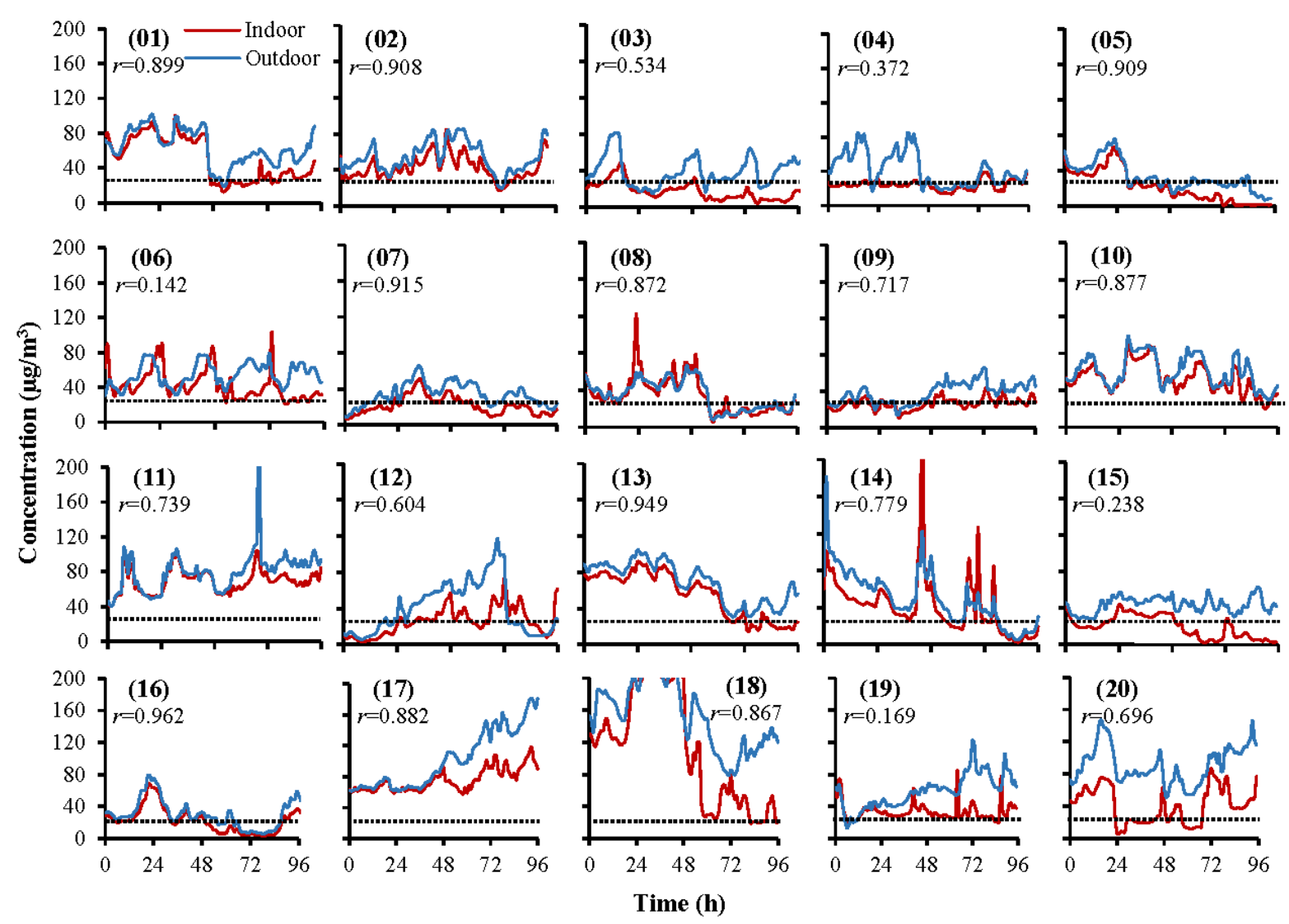

Figure 3. $\mathrm{PM}_{2.5}$ concentrations in indoor and outdoor air during the inspection. The red line represents the indoor $\mathrm{PM}_{2.5}$ concentration, and the blue line represents the outdoor $\mathrm{PM}_{2.5}$ concentration. The black dotted line $\left(25 \mu \mathrm{g} / \mathrm{m}^{3}\right)$ represents the WHO air quality guideline that is based on the relation between $24-\mathrm{h}$ and annual $\mathrm{PM}_{2.5}$ levels. 


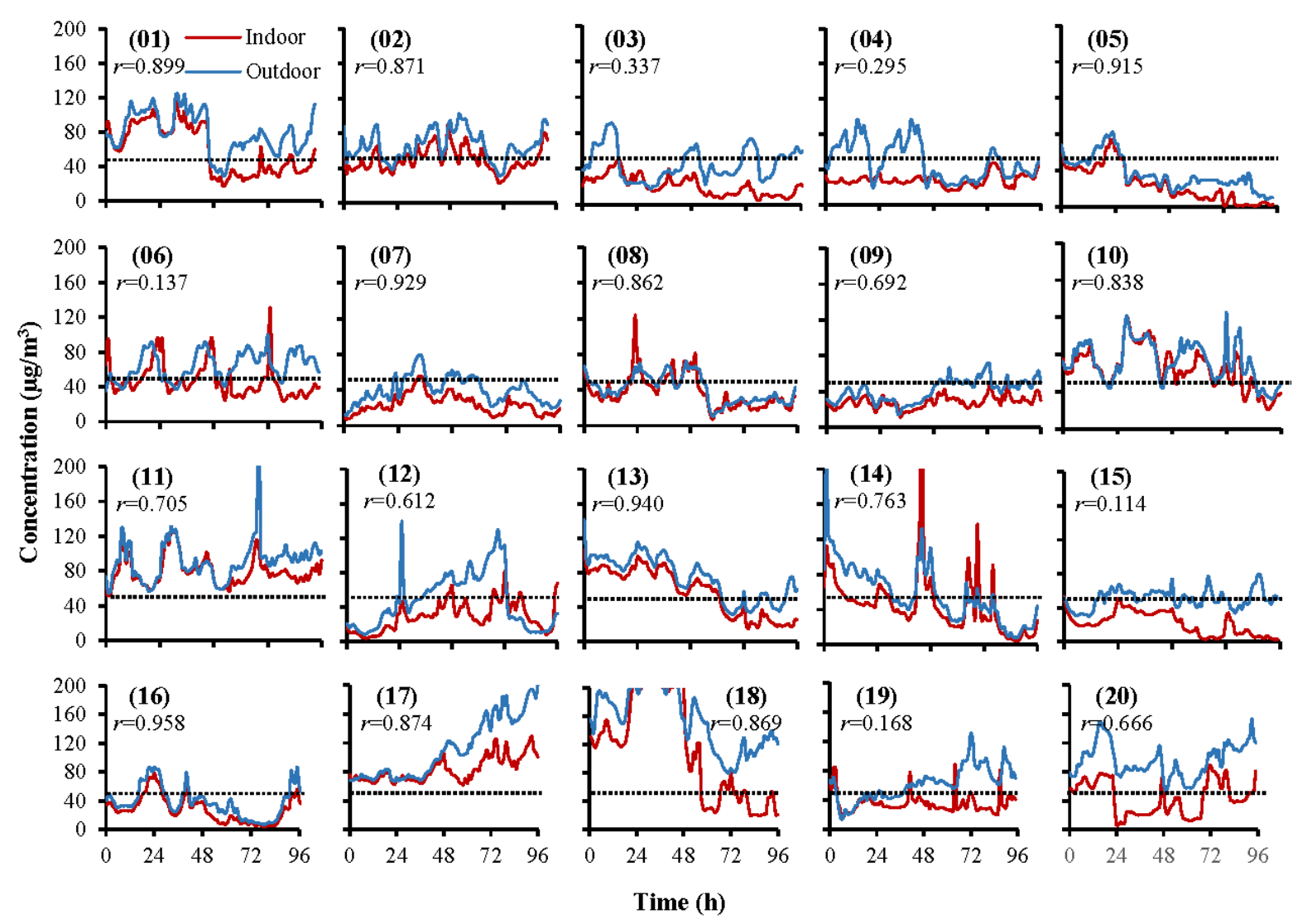

Figure 4. $\mathrm{PM}_{10}$ concentrations in indoor and outdoor air during the inspection. The red line represents the indoor $\mathrm{PM}_{10}$ concentration, and the blue line represents the outdoor $\mathrm{PM}_{10}$ concentration. The black dotted line $\left(50 \mu \mathrm{g} / \mathrm{m}^{3}\right)$ represents the $\mathrm{WHO}$ air quality guideline for $\mathrm{PM}_{10}$. 


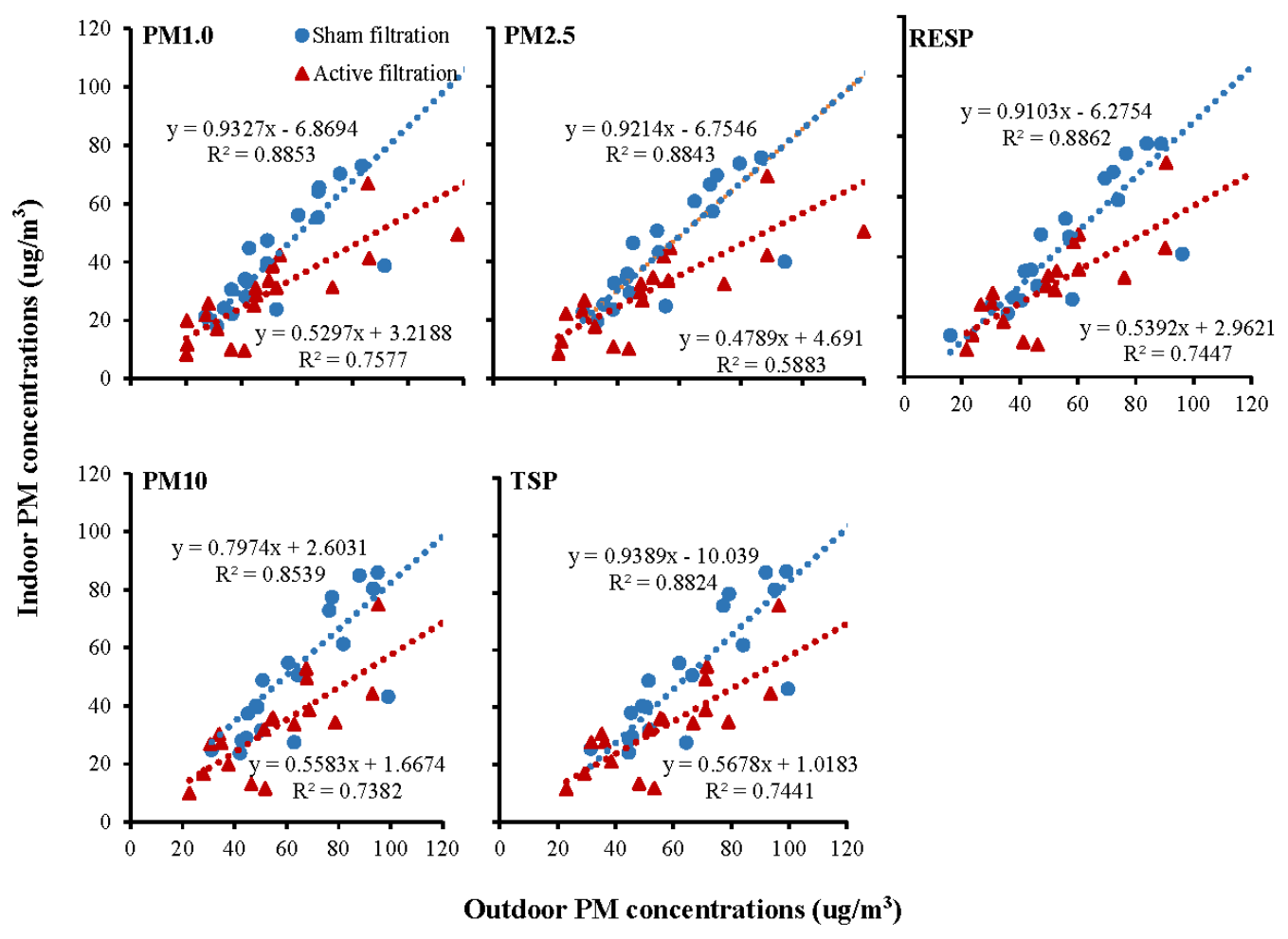

Figure 5. The linear fitting models for indoor and outdoor PM concentrations. 


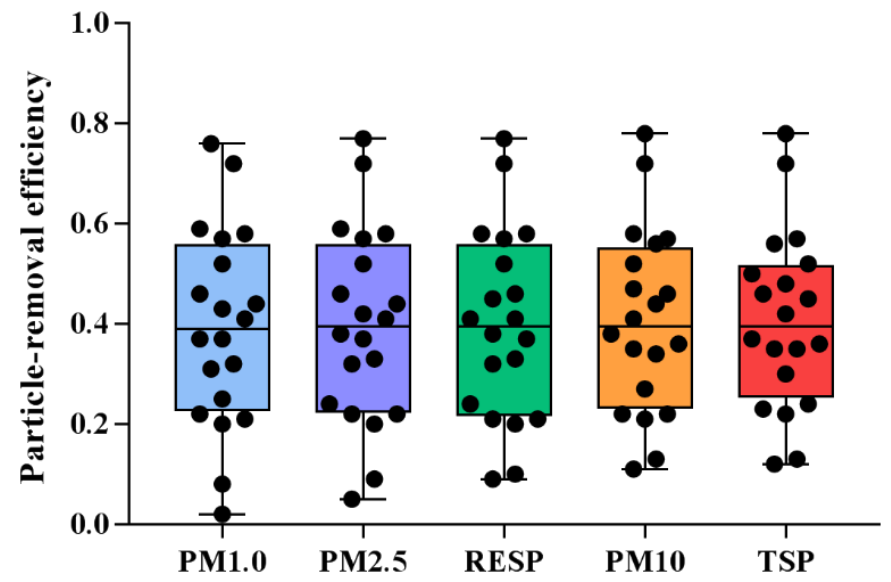

Figure 6. The particle-removal efficiencies for different particles. 
Table 1. Building characteristics of the residences used in the inspections.

\begin{tabular}{|c|c|c|c|c|c|c|c|c|}
\hline \multirow{2}{*}{$\begin{array}{l}\text { Residence } \\
\text { code }\end{array}$} & \multirow[b]{2}{*}{ District } & \multirow{2}{*}{$\begin{array}{l}\text { Inspected } \\
\text { season }\end{array}$} & \multirow{2}{*}{$\begin{array}{l}\text { Building } \\
\text { age }\end{array}$} & \multirow{2}{*}{$\begin{array}{l}\text { Floor } \\
\text { level }\end{array}$} & \multirow{2}{*}{$\begin{array}{l}\text { Room } \\
\text { volume } \\
\left(\mathrm{m}^{3}\right)\end{array}$} & \multirow{2}{*}{$\begin{array}{l}\text { Window } \\
\text { opening }\end{array}$} & \multicolumn{2}{|l|}{ Weather } \\
\hline & & & & & & & $\begin{array}{l}\text { Without } \\
\text { filter }\end{array}$ & $\begin{array}{l}\text { With } \\
\text { filter }\end{array}$ \\
\hline (01) & Shapingba & Summer & 2006 & 2 & 31.82 & Opened & Sunny & Sunny \\
\hline$(02)$ & Yuzhong & Summer & 2013 & 5 & 75.50 & Opened & Sunny & Sunny \\
\hline (03) & Jiangbei & Summer & 2012 & 32 & 87.90 & Closed & Rainy & Rainy \\
\hline (04) & Yuzhong & Summer & 2009 & 20 & 94.53 & Opened & Rainy & Cloudy \\
\hline (05) & Jiulongpo & Summer & 2014 & 4 & 55.92 & Opened & Sunny & Rainy \\
\hline (06) & Yubei & Summer & 2005 & 2 & 99.83 & Opened & Sunny & Sunny \\
\hline (07) & Shapingba & Autumn & 2010 & 25 & 38.65 & Opened & Rainy & Rainy \\
\hline (08) & Shapingba & Autumn & 2008 & 23 & 91.45 & Opened & Rainy & Rainy \\
\hline (09) & Jiangbei & Autumn & 2009 & 13 & 72.12 & Opened & Rainy & Cloudy \\
\hline (10) & Jiangbei & Autumn & 2008 & 23 & 94.76 & Opened & Sunny & Rainy \\
\hline (11) & Jiangbei & Autumn & 2012 & 32 & 79.59 & Opened & Cloudy & Rainy \\
\hline (12) & Dadukou & Autumn & 2012 & 7 & 89.00 & Opened & Rainy & Rainy \\
\hline (13) & Shapingba & Autumn & 2006 & 3 & 40.85 & Opened & Rainy & Rainy \\
\hline (14) & Shapingba & Autumn & 2009 & 3 & 97.80 & Closed & Rainy & Rainy \\
\hline (15) & Shapingba & Autumn & 2012 & 3 & 66.89 & Opened & Rainy & Cloudy \\
\hline (16) & Yubei & Autumn & 2013 & 27 & 66.95 & Closed & Cloudy & Rainy \\
\hline (17) & Shapingba & Winter & 2005 & 26 & 61.45 & Opened & Rainy & Cloudy \\
\hline (18) & Shapingba & Winter & 2009 & 30 & 67.33 & Closed & Cloudy & Cloudy \\
\hline (19) & Shapingba & Winter & 1990 & 3 & 35.78 & Closed & Cloudy & Rainy \\
\hline (20) & Shapingba & Winter & 1995 & 8 & 32.47 & Closed & Rainy & Rainy \\
\hline
\end{tabular}


Table 2. Comparisons of PM concentrations between indoor and outdoor air when an air cleaner was used without and with a HEPA filter.

\begin{tabular}{|c|c|c|c|c|}
\hline \multirow{2}{*}{ Items } & \multicolumn{2}{|l|}{ Mean \pm SD } & \multirow{2}{*}{$p$-value ${ }^{a}$} & \multirow{2}{*}{ Correlation coefficient, $r$ ( $p$-value) } \\
\hline & Outdoor & Indoor & & \\
\hline \multicolumn{5}{|c|}{ Sham filtration } \\
\hline $\mathrm{PM}_{1.0}$ & $59.0 \pm 34.4$ & $48.2 \pm 34.1$ & 0.323 & $0.941(<0.001)$ \\
\hline $\mathrm{PM}_{2.5}$ & $62.1 \pm 35.4$ & $50.4 \pm 34.7$ & 0.300 & $0.940(<0.001)$ \\
\hline RESP & $63.2 \pm 37.1$ & $51.2 \pm 35.9$ & 0.307 & $0.941(<0.001)$ \\
\hline $\mathrm{PM}_{10}$ & $70.0 \pm 36.0$ & $56.1 \pm 35.8$ & 0.227 & $0.936(<0.001)$ \\
\hline TSP & $71.5 \pm 36.0$ & $57.1 \pm 36.0$ & 0.214 & $0.939(<0.001)$ \\
\hline \multicolumn{5}{|c|}{ True filtration } \\
\hline $\mathrm{PM}_{1.0}$ & $52.9 \pm 30.8$ & $31.2 \pm 18.7$ & 0.011 & $0.870(<0.001)$ \\
\hline $\mathrm{PM}_{2.5}$ & $55.4 \pm 31.4$ & $32.7 \pm 19.3$ & 0.009 & $0.867(<0.001)$ \\
\hline RESP & $57.7 \pm 31.6$ & $34.1 \pm 19.8$ & 0.007 & $0.863(<0.001)$ \\
\hline $\mathrm{PM}_{10}$ & $62.4 \pm 32.0$ & $36.5 \pm 20.8$ & 0.004 & $0.859(<0.001)$ \\
\hline TSP & $63.9 \pm 33.5$ & $37.3 \pm 21.1$ & 0.004 & $0.863(<0.001)$ \\
\hline
\end{tabular}

${ }^{\text {a }}$ Significance for the differences in PM concentrations between indoor and outdoor air in the independentsample $t$-tests. 
Table 3. Evaluation of infiltration factor in the RCS model by linear fitting.

\begin{tabular}{|c|c|c|c|c|}
\hline Items & $F_{I N F}{ }^{\mathrm{a}}, \operatorname{Mean}(95 \% \mathrm{CI})$ & $\mathrm{R}^{2}$ & $p$-value ( $t$-test) & $p$-value $(F$-test $)$ \\
\hline \multicolumn{5}{|l|}{$\mathrm{PM}_{1.0}$} \\
\hline Sham filtration & $0.933(0.766-1.099)$ & 0.885 & $<0.001$ & $<0.001$ \\
\hline True filtration & $0.530(0.381-0.678)$ & 0.758 & $<0.001$ & $<0.001$ \\
\hline \multicolumn{5}{|l|}{$\mathrm{PM}_{2.5}$} \\
\hline Sham filtration & $0.921(0.756-1.087)$ & 0.884 & $<0.001$ & $<0.001$ \\
\hline True filtration & $0.535(0.383-0.687)$ & 0.752 & $<0.001$ & $<0.001$ \\
\hline \multicolumn{5}{|l|}{ RESP } \\
\hline Sham filtration & $0.910(0.749-1.072)$ & 0.886 & $<0.001$ & $<0.001$ \\
\hline True filtration & $0.539(0.383-0.696)$ & 0.745 & $<0.001$ & $<0.001$ \\
\hline \multicolumn{5}{|l|}{$\mathrm{PM}_{10}$} \\
\hline Sham filtration & $0.931(0.758-1.104)$ & 0.876 & $<0.001$ & $<0.001$ \\
\hline True filtration & $0.558(0.394-0.723)$ & 0.738 & $<0.001$ & $<0.001$ \\
\hline \multicolumn{5}{|l|}{ TSP } \\
\hline Sham filtration & $0.939(0.769-1.109)$ & 0.882 & $<0.001$ & $<0.001$ \\
\hline True filtration & $0.568(0.403-0.733)$ & 0.744 & $<0.001$ & $<0.001$ \\
\hline
\end{tabular}

${ }^{a} F_{I N F}$ (infiltration factor) represents the ratio of the contribution of ambient sources to indoor air PM concentrations; data were calculated by linear regression and were evaluated with $95 \%$ confidence intervals. 
Table 4. Removal efficiency for PM in the inspected residences under different conditions.

\begin{tabular}{lllllll}
\hline Items & Sample size, $n(\%)$ & $\mathrm{PM}_{1.0}$ & $\mathrm{PM}_{2.5}$ & RESP & $\mathrm{PM}_{10}$ & TSP \\
\hline Total & $20(100)$ & $0.39 \pm 0.20$ & $0.40 \pm 0.19$ & $0.40 \pm 0.19$ & $0.41 \pm 0.18$ & $0.41 \pm 0.18$
\end{tabular}

\section{Residence-located district}

$\begin{array}{lllllll}\text { Shapingba } & 9(45.0) & 0.37 \pm 0.20 & 0.38 \pm 0.19 & 0.39 \pm 0.18 & 0.39 \pm 0.17 & 0.39 \pm 0.17 \\ \text { Jiangbei } & 5(25.0) & 0.46 \pm 0.27 & 0.46 \pm 0.27 & 0.46 \pm 0.27 & 0.46 \pm 0.27 & 0.47 \pm 0.27 \\ \text { Others a } & 6(30.0) & 0.37 \pm 0.14 & 0.36 \pm 0.14 & 0.36 \pm 0.14 & 0.38 \pm 0.13 & 0.38 \pm 0.10\end{array}$

\section{Inspection season}

$\begin{array}{lllllll}\text { Summer } & 6(30.0) & 0.44 \pm 0.20 & 0.43 \pm 0.20 & 0.43 \pm 0.20 & 0.45 \pm 0.19 & 0.45 \pm 0.17 \\ \text { Autumn } & 10(50.0) & 0.32 \pm 0.21 & 0.33 \pm 0.21 & 0.33 \pm 0.20 & 0.34 \pm 0.20 & 0.35 \pm 0.19 \\ \text { Winter } & 4(20.0) & 0.51 \pm 0.10 & 0.51 \pm 0.10 & 0.51 \pm 0.10 & 0.51 \pm 0.10 & 0.50 \pm 0.10\end{array}$

\section{Building age of the residential building}

$\begin{array}{lllllll}<2007 & 6(30.0) & 0.44 \pm 0.09 & 0.44 \pm 0.09 & 0.44 \pm 0.09 & 0.45 \pm 0.09 & 0.45 \pm 0.09 \\ 2007-2010 & 7(35.0) & 0.27 \pm 0.20 & 0.28 \pm 0.20 & 0.29 \pm 0.19 & 0.30 \pm 0.18 & 0.30 \pm 0.17 \\ >2010 & 7(35.0) & 0.47 \pm 0.22 & 0.47 \pm 0.23 & 0.46 \pm 0.23 & 0.47 \pm 0.22 & 0.47 \pm 0.21\end{array}$

Floor level of the inspected room

$\begin{array}{lllllll}\leq 10 & 10(50.0) & 0.43 \pm 0.20 & 0.43 \pm 0.20 & 0.43 \pm 0.19 & 0.44 \pm 0.19 & 0.44 \pm 0.17 \\ >10 & 10(50.0) & 0.36 \pm 0.20 & 0.36 \pm 0.20 & 0.36 \pm 0.19 & 0.37 \pm 0.18 & 0.37 \pm 0.18\end{array}$

Window opening during inspection

$\begin{array}{lllllll}\text { Opened } & 14(70.0) & 0.35 \pm 0.18 & 0.36 \pm 0.18 & 0.36 \pm 0.17 & 0.37 \pm 0.17 & \mathbf{0 . 3 7} \pm \mathbf{0 . 1 6} \\ \text { Closed } & 6(30.0) & 0.48 \pm 0.22 & 0.48 \pm 0.22 & 0.48 \pm 0.22 & 0.48 \pm 0.21 & \mathbf{0 . 4 9} \pm \mathbf{0 . 2 0} *\end{array}$

Volume of the inspected room
$<60 \mathrm{~m}^{3} \quad 6(30.0)$

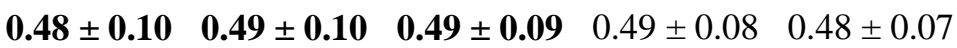
$60-80 \mathrm{~m}^{3} \quad 7(35.0)$

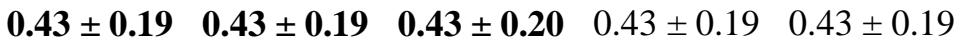
$>80 \mathrm{~m}^{3}$
$7(35.0)$
$\boldsymbol{0 . 2 8} \pm \mathbf{0 . 2 3}^{*} \mathbf{0 . 2 9} \pm \mathbf{0 . 2 3}^{*} \mathbf{0 . 2 9} \pm \mathbf{0 . 2 2} * 0.31 \pm 0.21 \quad 0.32 \pm 0.21$

Ambient weather during inspection

\begin{tabular}{lllllll} 
Rainy & $12(60.0)$ & $0.37 \pm 0.21$ & $0.38 \pm 0.21$ & $0.38 \pm 0.20$ & $0.38 \pm 0.19$ & $0.38 \pm 0.18$ \\
Cloudy/sunny & $8(40.0)$ & $0.42 \pm 0.18$ & $0.42 \pm 0.18$ & $0.43 \pm 0.18$ & $0.44 \pm 0.18$ & $0.44 \pm 0.17$ \\
\hline
\end{tabular}

a Others category includes the Yuzhong district, Yubei district, Jiulongpo district, and Dadukou district.

${ }^{*} p$-value $<0.05$ in the one-way ANOVA tests. 